\title{
End-to-End Demonstrator of the Safe Affordable Fission Engine (SAFE) 30: Power Conversion and Ion Engine Operation
}

\author{
Ivana Hrbud ${ }^{1}$, Melissa Van Dyke ${ }^{1}$, Mike Houts ${ }^{1}$, Keith Goodfellow ${ }^{2}$ \\ ${ }^{I}$ NASA Marshall Space Flight Center, Propulsion Research Center, Huntsville, AL 35812 \\ ${ }^{2}$ NASA Jet Propulsion Laboratory, Pasadena, CA 91109 \\ (256) 544-2465, Ivana.Hrbud@msfc.nasa.gov
}

\begin{abstract}
The Safe Affordable Fission Engine (SAFE) test series addresses Phase 1 Space Fission Systems issues in particular non-nuclear testing and system integration issues leading to the testing and non-nuclear demonstration of a $400-\mathrm{kW}$ fully integrated flight unit. The first part of the SAFE 30 test series demonstrated operation of the simulated nuclear core and heat pipe system. Experimental data acquired in a number of different test scenarios will validate existing computational models, demonstrated system flexibility (fast start-ups, multiple start-ups/shut downs), simulate predictable failure modes and operating environments. The objective of the second part is to demonstrate an integrated propulsion system consisting of a core, conversion system and a thruster where the system converts thermal heat into jet power. This end-to-end system demonstration sets a precedent for ground testing of nuclear electric propulsion systems. The paper describes the SAFE 30 end-to-end system demonstration and its subsystems.
\end{abstract}

\section{INTRODUCTION}

Rapid access to any point in the solar system and beyond requires advanced propulsion concepts that can provide extremely high specific impulse, high specific power, and high thrust-to-power ratios. NASA's vision for the $21^{\text {st }}$ century and beyond is challenging scientific and engineering communities to develop propulsion technologies which wiil enabie ambitious expioration of the soiar system and its intersteliar neighborhood, commercialization of space, and eventual human colonization beyond Earth (Schmidt, 1998). Two technologies that synergistically offer tremendous potential for the immediate future are advanced electric propulsion and nuclear energy. Space nuclear systems have recently received a renewed interest due to their versatility, high-power density, and ability to support power-intensive missions (Borowski et al., 1998). The dualism of providing both propulsion and power, linked with the enormous energy available per unit mass of fission fuel, has significant benefits to future programs involving nuclear thermal rockets (Watson, 1994), efficient conversion systems, space-based nuclear reactors, and nuclear electric propulsion (Allen, 1995).

To date, only a few electric propulsion concepts can support the high power requirements for future missions. Due to their specific impulse operating range, advanced ion and Hall thrusters (Sankovic, 1999) are the most likely candidates to be used in the near term for a wide variety of missions spanning from Low Earth Orbit to interstellar space. Depending on the mission scenario/profile, this efficient electric propulsion device can be powered by solar or space nuclear power. Beyond the use of these very efficient systems, mid to far term solution might include propulsion concepts such as the MagnetoPlasmaDynamic (MPD) thruster (Polk, 1999, LaPointe, 2000), the Variable Specific Impulse Magnetoplasma Rocket (VaSIMR) (Chang-Diaz, 1995), the Pulsed Inductive thruster (PIT) (Dailey, 1993).

Research in the field of electrostatic acceleration has been conducted since the late 1950s' resulting in a number of different devices and ionization methods capable of supporting space propulsion. These devices use suitable grid electrodes for ion extraction/acceleration converting electric energy to kinetic energy. The most commonly used ion source is based on electron bombardment where plasma is generated by electrons colliding with neutral gas. 
Thrusters based on the Kaufman concept use weak magnetic fields for ion/electron separation. To date, the most successful ion thruster developed by NASA is the NSTAR engine, which currently flies on board the Deep Space 1 (DS 1) spacecraft.

\section{SAFE 30 TEST SERIES}

Power of $10-100 \mathrm{~kW}$ and specific power of $10-30 \mathrm{~kg} / \mathrm{kW}$ characterize Phase 1 Space Fission Systems (SFS) possibly used for nuclear electric propulsion (NEP) and spacecraft/surface powerplants. These systems are targeted for, but are not limited to, space science missions extending from planetary orbiters and landers to interstellar precursor probes. The Safe Affordable Fission Engine (SAFE) test series addresses some system issues of Phase 1 SFS in particular non-nuclear testing and system integration issues leading to the testing and non-nuclear demonstration of a 400-kW fully integrated flight unit. The SAFE test program (van Dyke, 2001) has a phased structure/approach, which started with module testing (MUTT) (van Dyke 2000) and will be completed with a full propulsion system demonstrator including core, thruster, reflectors, radiators, etc.

The SAFE 30 is a full core test designed for a power input of $30 \mathrm{~kW}$ using resistance heating to simulate the thermal heat from a fission reactor. The core has a hexagonal footprint of 48 stainless steel tubes and 12 stainless steel sodium filled heat pipes. It is assembled in a modular fashion where a module consists of 4 stainless steel tubes and one heat pipe welded together longitudinally. The heat pipes are $119 \mathrm{~cm}$ and the tubes are $43 \mathrm{~cm}$ long, while the diameter of both is $2.54 \mathrm{~cm}$. Resistance heaters, which are inserted into the stainless steel tubes, are made from graphite rods and are rated for up to $1.3 \mathrm{~kW}\left(0.34 \Omega\right.$ at $\left.1000{ }^{\circ} \mathrm{C}\right)$. The heaters generate thermal heat closely simulating the thermal profile of an actual nuclear (fission) system. The nominal power input to a heater is about $750 \mathrm{~W}$ generating a temperature of $1000{ }^{\circ} \mathrm{C}$. The heat pipes embedded in the core remove the heat out of the core where the maximum isothermal operating temperature for the heat pipes is about $750{ }^{\circ} \mathrm{C}$. Figure 1 illustrates an infrared picture of the SAFE 30 core where the glowing heat pipes are in the background and the foreground shows the heater electrical interface. Figure 2 depicts a typical temperature profile of the heat pipes in the core and outside the core (us=upstream/ds=downstream of copper heat exchanger, see below) as a function of time during a test series at JPL in May 2001.

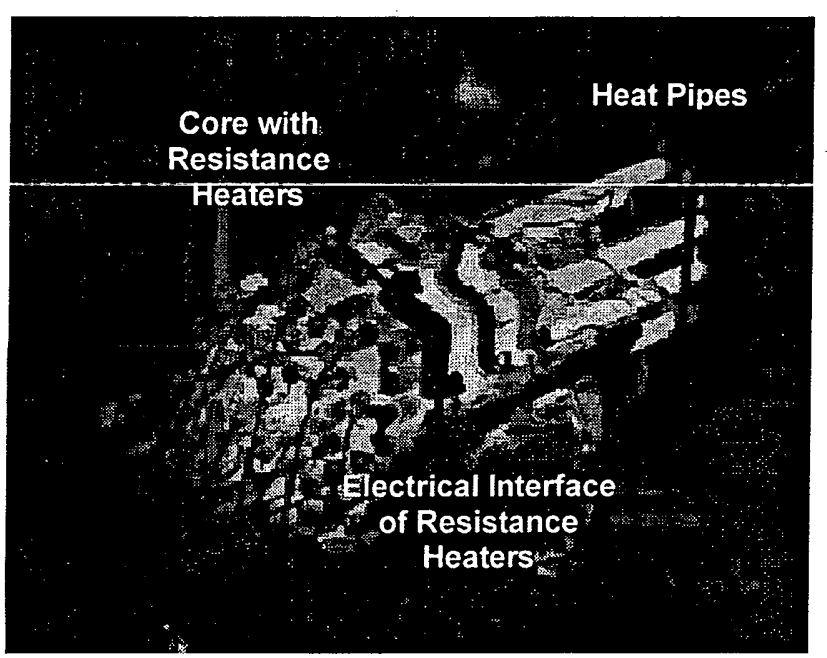

FIGURE 1. Infrared Picture of Simulated Resistance-Heated Core and Heat Pipes at about $650^{\circ} \mathrm{C}$.

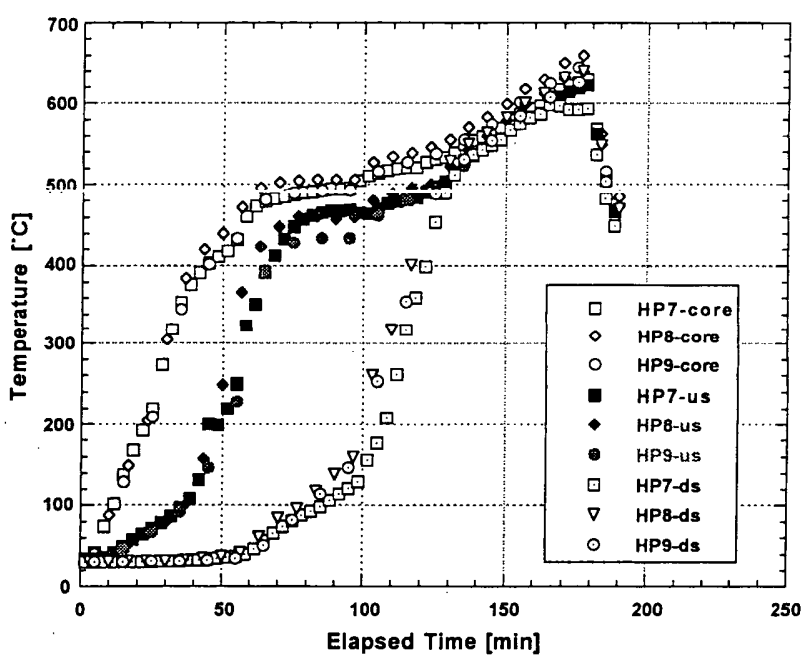

FIGURE 2. Typical Temperature Behavior as Function of Time.

The goal of the first part of the SAFE 30 test series was to obtain experimental data demonstrating operation of the simulated nuclear core and heat pipe system. Experimental data acquired in a number of different test scenarios will validate existing computational models, demonstrated system flexibility (fast start-ups, multiple start-ups/shut downs), simulate predictable failure modes and operating environments. The objective of the second part is to demonstrate an integrated propulsion system consisting of a core, conversion system and a thruster where the system converts thermal heat into jet power. 


\section{ION THRUSTER - BACKGROUND}

Ion thrusters are characterized by continuous, low to moderate power level operation while electrostatically accelerating positively charged particles (atomic/molecular ions, colloidal particles, etc.). The characterization of electrostatic systems is based on the production mechanisms of charged particles; these can be summarized as electron bombardment, RF ionization, contact/surface and field emission ionization. The main components of a Kaufman type ion thruster are discharge chamber containing magnet system and electron emitter (hollow cathode), optics/acceleration grids, neutralizer hollow cathode, and power supplies for each subsystem. Figure 3 illustrates a schematic of such a thruster whose ion source is based on electron bombardment (using electron bombardment to produce ions). The hollow cathode produces and emits electrons into the discharge cavity of the thruster. These primary electrons drift towards the anode transversing a weak axial magnetic field, which causes a spiral motion. The electrons collide and ionize neutral atoms injected into the discharge chamber. The magnetic field prevents premature losses of primary electrons to the anode and ion losses to thruster walls. The electron kinetic energy and the diameter of the discharge chamber determine the strength of the magnetic field, which can be provided by either a permanent or electro magnet. The high electrostatic potential established between the plasma and the acceleration grid extracts and accelerates ions. A cathode at the exit plane of the thruster emits electrons to neutralize the ion beam. It is crucial for the operation of this thruster to keep the net charge of the beam zero. The thrust and specific impulse depend on net acceleration potential, mass-to-charge ratio of the ion and the ion density.
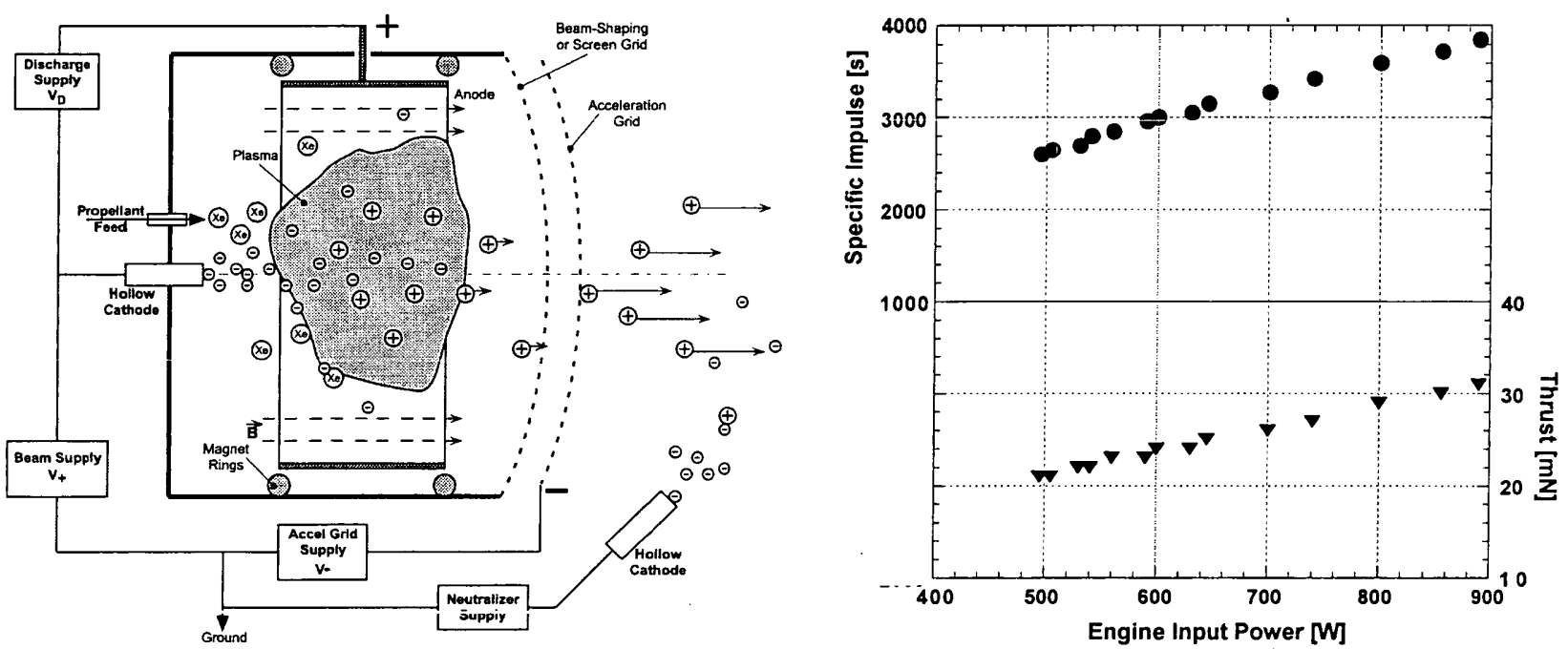

FIGURE 3. Schematic of Ion Thruster.

FIGURE 4. Specific Impulse and Thrust as a Function of Input Power (data extracted with permission from Brophy 1993)

Ion thrusters have been developed and tested since the 1950's accumulating an extensive laboratory and flight history. The first ion thruster ever flown was SERT I (Space Electric Rocket Test, 1964), which used vaporized Mercury as propellant (Cybulski, 1965). The latest in a long list of successfully used ion thrusters in space is the 30cm NSTAR ion thruster propelling the Deep Space 1 (DS 1) spacecraft, which flew by an asteroid and the comet 'Borrelly'. The thruster was designed for $2.3 \mathrm{~kW}$ and a beam voltage of $1,000 \mathrm{~V}$ using Xenon as propellant. Inflight performance characteristics include specific impulse of 3,200 s and thrust of $120 \mathrm{mN}$ resulting in an overall efficiency of $62 \%$. As of September 24, 2001, marking the day of the fly-by at the comet, the thruster logged more than 14,200 hours of (continuous) operation with a propellant through-put of $65 \mathrm{~kg}$. While the performance of the flight unit is carefully monitored, a spare NSTAR ion thruster is pushed to the limit in ground testing at the JPL test facilities. The spare unit accumulated 18,800 hours of operation and expended $155 \mathrm{~kg}$ of Xenon (Brophy, 2001).

The demand of future planetary missions, the need to reduce launch cost and to significantly extend mission lifetime motivated the push for the development of a scaled down version of the successful $30-\mathrm{cm}$ NSTAR ion engine. A program was established to 1.) develop a $15-\mathrm{cm}$ Xenon ion thruster, 2.) explore a cluster configuration of four $15-\mathrm{cm}$ ion thrusters and 3.) provide a testbed for advanced acceleration optics and materials (Brophy, 1993). To date, advanced grid technologies include optics fabricated from diamond film, dished graphite grids, molybdenum and carbon-carbon (Mueller, 1993) acceleration systems. 
The $15-\mathrm{cm}$ ion engine is designed for a maximum input power (to the power processing unit) of $1.25 \mathrm{~kW}$, while it can be safely operated at a beam power as low as $200 \mathrm{~W}$. Figure 4 illustrates a typical trend for specific impulse and thrust as a function of power input. Operating the ion thruster at a constant beam current of $500 \mathrm{~mA}$, this data was obtained with molybdenum grids. Performance characteristics with carbon-based grid materials are comparable, although in general performance values are slightly lower. However, carbon-based grids supersede with extremely low erosion rate and superior sputter resistance. These properties are key to significantly extend the lifetime of ion thrusters. Preliminary performance evaluation for molybdenum and graphite grids indicates a total thruster efficiency of about 52 to $66 \%$ with an uncertainty of up to $10 \%$ (Brophy, 1993). Figure 6 shows the 15-cm, slotted Carbon-Carbon grid ion thruster as it is mounted to the door of the vacuum chamber at the JPL facilities. The set-in picture is an enlarged section of the grid revealing the slot structure.

\section{END-TO-END SYSTEM DEMONSTRATION}

The end-to-end system demonstration consists of the SAFE 30 simulated core, 350-W Stirling engine, DC/DC converter and $15-\mathrm{cm}$ ion thruster with slotted carbon-carbon grids. The purpose of the end-to-end tests is to showcase the nuclear electric propulsion (NEP) concept -using thermal heat released by fission processes and converting that heat to kinetic energy- by a simulated approach with inexpensive off-the-shelf materials in a relevant environment.

For the end-to-end system demonstration, the SAFE 30 core is assembled in its modular manner and consists of two heating zones each powered by a separate power supply. Zone One encompasses three modules containing heat pipes. There are three strings of heaters wired in parallel where each string contains four heaters in series. These twelve heaters are powered by a HP power supply providing $100 \mathrm{~A}$ at $100 \mathrm{VDC}$. The remaining nine modules comprise Zone Two which is provided with heating power by a 400-A, 200-VDC Linde power supply. A module in this zone has four stainless steel tubes welded to a blanked-off pipe of the same dimensions as the heat pipe. The heaters are wired in 18 parallel strings where each string contains two heaters in series.

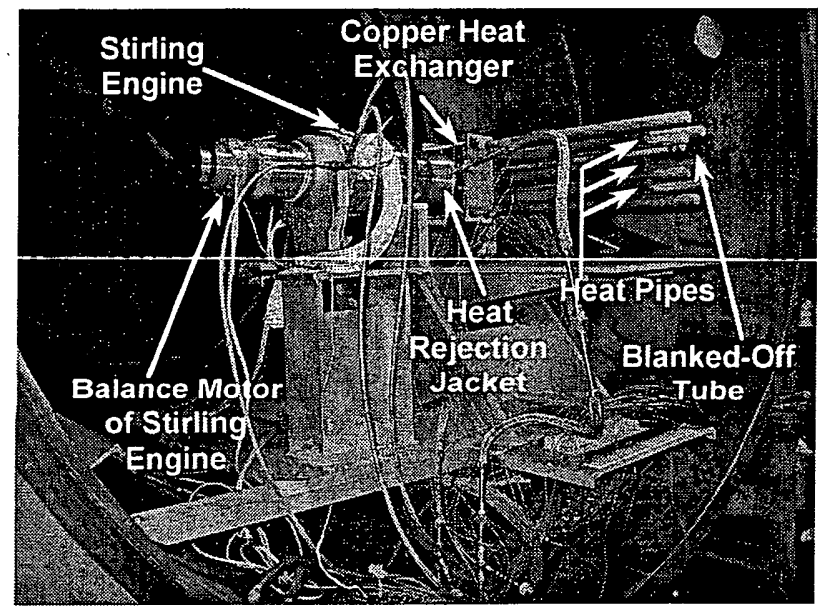

FIGURE 5. Heat Source and Conversion System. Mounted in the Vacuum Chamber at JPL.

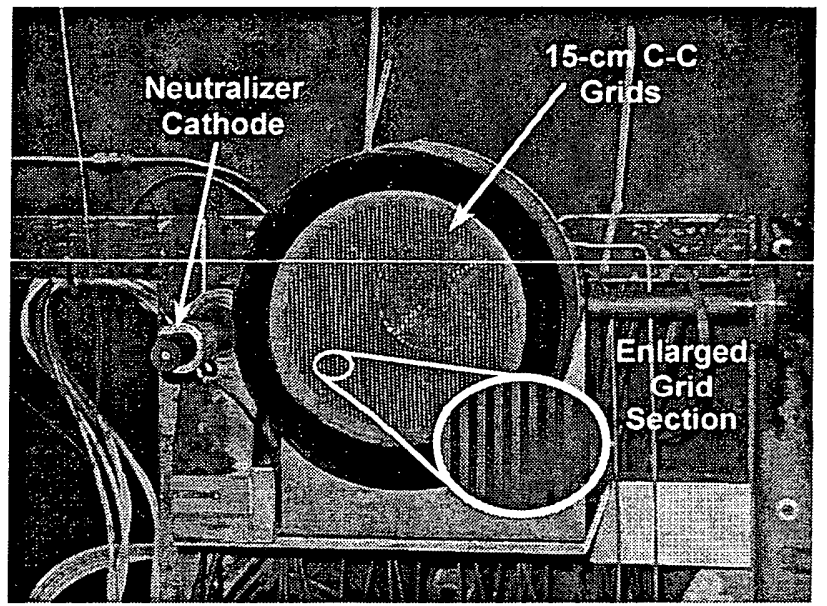

FIGURE 6. $15-\mathrm{cm}$, Slotted Carbon-Carbon Grid Ion Thruster.

As it is illustrated in Figure 5, the protruding three heat pipes are clamped to a copper block, which in turn is attached to the heater head of the 350-W Stirling engine. The Stirling engine is an (production line) off-the-shelf device manufactured by Stirling Technology Company (STC). The Stirling engine converts thermal energy into electric energy based on the thermodynamic process described by the Stirling cycle outlined elsewhere (Schreiber, 2001). This engine is based on the 'free-piston' power conversion concept using thermal-mechanical oscillations to drive a linear alternator. The efficiency of a Stirling cycle can be maintained over a wide range of power and can approach Carnot efficiencies. The active heat exchange zone on the heater head is about $4.5 \mathrm{~cm}$ wide operating at a nominal temperature of $650^{\circ} \mathrm{C}$. The copper block clamps precisely over that region to ensure proper heat input to the heater head of the Stirling engine. The Stirling engine is equipped with a balance motor compensating for vibrations generated by the engine during entire operation sequence (initial start-up, power generation, shut-down). 
The working fluid of the engine is Helium at a pressure of 45 to 52 bar, while the alternator generates $350 \mathrm{~W}$ at 175 VAC.

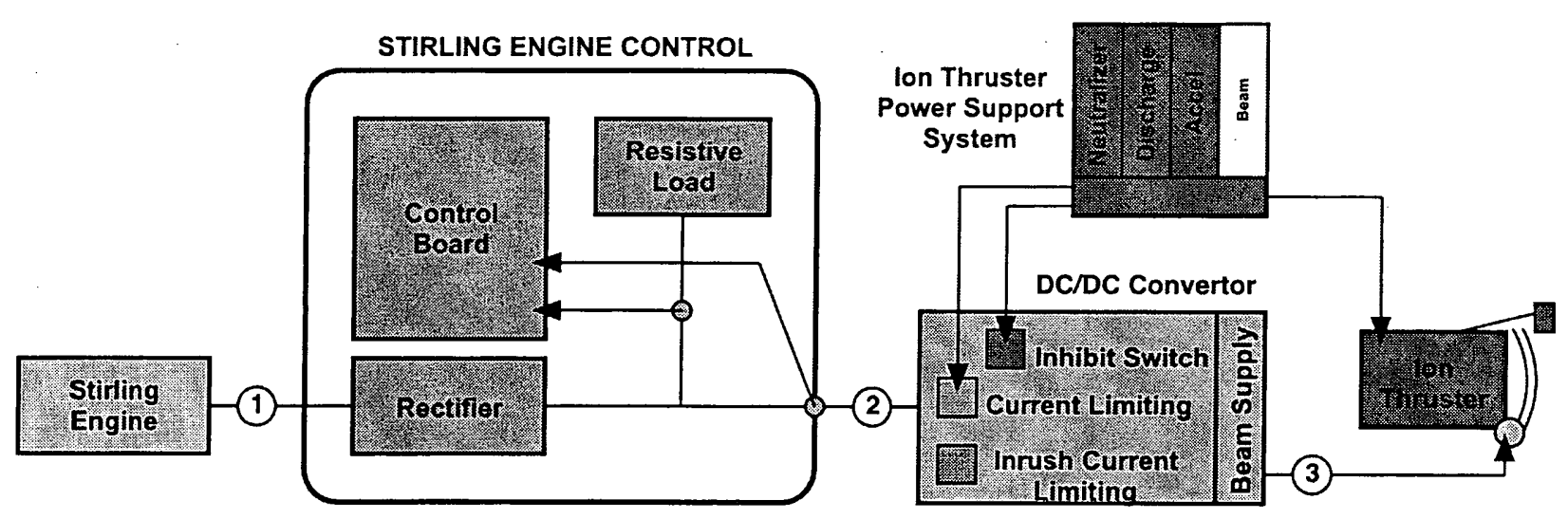

FIGURE 7. Schematic of the Powertrain Providing Beam Power to the Ion Thruster from the Stirling Engine.

The power support system for the ion thruster consists of four separate power supplies providing power to the subsystems of the thruster as described above. However, the power generated by the Stirling engine replaces the conventional beam supply. All other subsystems of the thruster will be maintained and controlled by the power support system. The powertrain between the Stirling engine and the ion thruster is illustrated in Figure 7. The Stirling engine controller processes the generated power and provides logistics to the Stirling engine depending on operating conditions and power demand (load). The control board algorithm manages the proper loading of the Stirling engine. Sensing circuitry monitors power demand at the output and accordingly the control board ties in or removes stages of a resistive load array. The AC power generated by the Stirling engine is processes by rectifier circuitry and converted to an output of about $123 \mathrm{VDC}$ and $3 \mathrm{~A}$. A crucial component of the powertrain is the $\mathrm{DC} / \mathrm{DC}$ converter, which conditions the power for the beam supply of the ion thruster. The major functions of this device are voltage step-up, current and inrush current limitation, and power enable/inhibit control. The DC/DC converter steps up the input voltage of about $123 \mathrm{VDC}$ to $1000 \mathrm{VDC}$ with appropriate transformer circuitry. In addition, the device limits the inrush current during the start-up sequence of the ion thruster. Without appropriate protection circuitry during this period, the current drawn by the system could be very high damaging all crucial components of the powertrain. This circuit (consisting of an IGBT and capacitor array) monitors the input current to the converter. In the case that the rate of rise is ton high, the IGBTs are switched on and off at high frequency allowing the capacitor bank to charge at incremental current drawn during the pulses. The inhibit switch is another important part of the converter, which is controlled by the power support system of the ion thruster. The switch terminates the high voltage provided by the converter to the thruster in case of malfunction or system failure. The power support system provides a signal of $5 \mathrm{VDC}$ to engage the inhibit mode of the switch and a 0 -VDC signal to disengage the mode. Another feature of the converter is the external programming, which sets the maximum output current by a signal provided by the power support system. The input signal is between 0 and $5 \mathrm{~V}$, where the output current is $0 \mathrm{~A}$ at $0 \mathrm{~V}$ and $500 \mathrm{~mA}$ at $5 \mathrm{~V}$. Any desired output current within this limit follows a linear relationship depending on the input voltage. The DC/DC converter is rated for a power input of $500 \mathrm{~W}$ and its efficiency is about $90 \%$. Table 1 summarizes electrical characteristics of the powertrain at locations indicated in Figure 7.

TABLE 1. Expected Electrical Characteristics at Selected Locations of the Powertrain.

\begin{tabular}{lccc}
\hline Location & $\mathbf{1}$ & $\mathbf{2}$ & $\mathbf{3}$ \\
\hline Voltage & $170 \mathrm{VAC}$ & $123 \mathrm{VDC}$ & $1000 \mathrm{VDC}$ \\
Current & $2 \mathrm{~A}$ & $2.9 \mathrm{~A}$ & $300 \mathrm{~mA}$ \\
Power & $350 \mathrm{~W}$ & $350 \mathrm{~W}$ & $300 \mathrm{~W}$ \\
\hline
\end{tabular}

\section{CONCLUSIONS}

The end-to-end system demonstration sets a precedent for ground testing of nuclear electric propulsion systems. Simulating the thermal heat released by a nuclear core with resistance heaters is inexpensive and can be performed 
in a timely manner. More importantly, integration issues, system behavior/failure and component matters are quickly identified and accurately analyzed. The success of this program led by NASA MSFC is shared and depends on the collaboration with NASA centers, other government agencies, industry and academia. The combination of long life, low specific mass, and high specific impulse is unique among electric propulsion systems, making NEP systems well suited for the challenging missions envisioned by NASA.

\section{ACKNOWLEDGMENTS}

This program was funded through the NASA Advanced Space Transportation Program (ASTP), whose support is gratefully acknowledged. The authors wish to thank Dr. James Polk, JPL (Pasadena, CA), for facilitating the endto-end demonstration at JPL facilities; Dr. John R. Brophy, JPL (Pasadena, CA), for providing performance characteristics of the 15-cm, carbon-carbon grid ion thruster; Mr. Jack Augenblick and Mr. Iain Williford, Stirling Technology Company (Kennewick, WA), for providing technical assistance on the Stirling engine.

\section{REFERENCES}

Allen, D. M., Bennett, G. L., El-Genk, M. S., Newhouse, A. R., and Rose, M. F., "Maintenance of the U.S. Space Nuclear Power Program: An AIAA Position Paper," 46 ${ }^{\text {th }}$ International Astronautical Congress, IAF-95-R.1.05, Oslo, Norway, October 1995.

Borowski, S. K., Dudzinski, L. A., and McGuire, M. L., "Vehicle and Mission Design Options for the Human Exploration of Mars/Phobos Using Bimodal NTR and LANTR Propulsion," NASA/TM-1998-208834, December 1998.

Brophy, J.R., Personal Communication, November 2001.

Brophy, J. R., Pless, L. C., Mueller, J., Anderson, J. R., "Operating Characteristics of a 15-cm-Diameter Ion Engine for Small Planetary Spacecraft," International Electric Propulsion Conference, IEPC-93-110, September 1993, Seattle, WA.

Chang-Diaz, F. R., Braden, E., Johnson, I., Hsu, M. M., and Yang, T. F., "Rapid Mars Transits with Exhaust-Modulated Plasma Propulsion," NASA Technical Paper 3539, March 1995.

Cybulski, J. R., et. al., "Results from SERT I Ion Rocket Flight Test," NASA Technical Note D-2718, 1965.

Dailey, C. L. and Lovberg, R. H., "The PIT MkV Pulsed Inductive Thruster," NASA CR 191155, July 1993.

LaPointe, M. R. and Sankovic, J. M., "High Power Electromagnetic Propulsion at the NASA Glenn Research Center," Proceedings of the Space Technologies and International Forum (STAIF) 2000 Conference, American Institute of Physics Conference Proceedings 504, M. El-Genk (ed), January 2000, pp. 1538-43.

Mueller, J., Brown, D. K., Garner, C. E., Brophy, J. R., "Fabrication of Carbon-Carbon Grids for Ion Optics," International Electric Propulsion Conference, IEPC-93-112, September 1993, Seattle, WA.

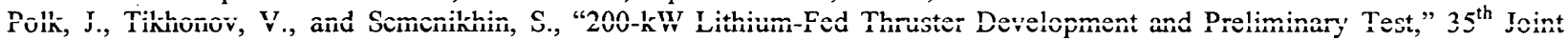
Propulsion Conference, AlAA 99-2285, Los Angeles, CA, June 1999.

Sankovic, J., Oleson, S. and LaPointe, M., "NASA GRC Activities in High Power Electric Propulsion," Proceedings of the NASA/JPL $10^{\text {th }}$ Advanced Space Propulsion Workshop, April 1999, pp. 665-681.

Schmidt, G. R., "Propulsion Research and Technology at NASA Marshall Space Flight Center," $34^{\text {th }}$ AIAA Joint Propulsion Conference, AIAA 98-3230, Cleveland, OH, July 1998.

Schreiber, J., "Tutorial on Free-Piston Stirling Power conversion Technology - How does it Work?," presented at the Space Technology and Applications International Forum (STAIF) 2001 Conference, Albuquerque, NM, February 2001.

van Dyke, M. K., Houts, M., Pederson, K., Godfroy, T., Dickens, R., Poston, D., Reid, R., Salvail, P., Ring, P. "Phase 1 Space Fission Propulsion System Testing and Development Progress," Proceedings of the Space Technologies and International Forum (STAIF) 2001 Conference, American Institute of Physics Conference Proceedings 552, M. El-Genk (ed), January 2000, pp. 1211-17.

van Dyke, M. K., Godfroy, T., Houts, M., Dickens, R., Dobson, C., Pederson, K., Reid, R., Sena, T. "Results of a First Generation Least Expensive Approach to Fission Module Tests: Non-Nuclear Testing of a Fission System," Proceedings of the Space Technologies and International Forum (STAIF) 2000 Conference, American Institute of Physics Conference Proceedings 504, M. El-Genk (ed), January 2000, pp. 1211-17.

Watson, C.W., "Nuclear Rockets: High-Performance Propulsion for Mars, " LA-12784-MS, Los Alamos National Laboratory, May 1994. 